\title{
THE ROLE OF AFFECTIVE EXPECTATIONS IN SUBJECTIVE EXPERIENCE AND DECISION-MAKING
}

\author{
KRISTEN J. KLAAREN \\ Randolph-Macon College \\ SARA D. HODGES AND TIMOTHY D. WILSON \\ University of Virginia
}

Two studies explored the extent to which prior affective expectations shape people's evaluations of experiences and decisions about repeating those experiences. Study 1 found that students' prior expectations about an upcoming vacation accounted for a significant portion of the variance in their post-vacation evaluations, as did students' recall of specific experiences. In Study 2, both prior expectations and actual experiences of watching a movie were manipulated in a $2 \times 2$ design. People's affective expectations made more of a difference than the objective experience when assessing people's willingness to participate in the study again. A reinterpretation hypothesis-that people discount or reweigh memories of expectation-inconsistent events-accounted for the results of these studies better than a selective memory or initial effects hypothesis.

Jared Diamond, the author and physiologist, frequently travels to New Guinea to study its birds. On a recent trip he was finally able to visit an extremely remote area, the Lakes Plain. Because he had always wanted to visit this part of New Guinea, Diamond expected to experience tremendous enjoyment and fulfillment at finally being able to do so. His experiences, however, were soon at great odds with his expectations:

The weather was so hot and humid that I felt myself overheating with every step. I longed to go shirtless for comfort but didn't dare because of the clouds of mosquitoes. Spiders were crawling through my hair, stinging ants had gotten inside my underwear, and the itching of chigger bites on my private parts was

The research described in this article was supported by National Institute of Mental Health Grant MH41841 to the third author. A previous version of this research was presented at the May, 1993 meeting of the Midwestern Psychological Association by the second author. We would like to thank the anonymous reviewers for very helpful comments and suggestions. Address all correspondence to Kristen J. Klaaren, Department of Psychology, Randolph-Macon College, Ashland, VA 23005. 
driving me crazy. Tiny gnats hovered in front of my eyes, awaiting the chance to dive into my tear ducts. Blood stains on my trousers marked the sites of fresh leech bites. (Diamond, 1991, p. 75)

By the time Diamond left New Guinea his leech bites were ulcerating, and he was suffering from fever and diarrhea. One might think that these horrible experiences would forever taint his memories of New Guinea and erase any future inclination to return. After a month had passed, however, Diamond's recollections of his visit seem to have been filtered through his original expectations about how he would feel:

My memories were already becoming more selective... what remained as vivid as ever was my sense of New Guinea's overpowering beauty, and my admiration for the people.... I look forward to returning." (p. 79)

Diamond's experiences suggest that at least at times, people's affective expectations-the emotions, evaluations, and preferences they anticipate having in a specific situation-influence the way they reconstruct their experiences, overriding, at least to some extent, what they actually experienced. As time passed, Diamond's strong, positive expectations about the Lakes Plain area of New Guinea and his positive feelings about the country as a whole, seemed to matter more than the extremely negative experiences he endured. Despite the spiders and leeches, he very much wanted to visit the country again.

The present studies were designed to explore whether our affective expectations shape our evaluations and memories of our experiences, as seems to have happened to Diamond. In addition, our research addressed the issue of whether the influence of affective expectations extends beyond memories and perceptions to decision-making activities. Are our affective reactions shaped in part by prior expectations about feelings? Does this assimilation process influence the decisions we make about repeating an activity?

Our hypothesis is that affective expectations can influence both actual experiences and decisions to repeat these experiences. Our approach is consistent with several recent theories of emotion that promote a theorydriven rather than exclusively data-driven approach to the study of affect. For example, the cognitive appraisal approach argues that emotion results from the appraisal of events in relation to people's needs, wishes, and expectations (Frijda, 1986; Ortony, Clore, \& Collins, 1988; Roseman, 1984; Shaver, Schwartz, Kirson, \& O'Connor, 1987; Smith \& Pope, 1992; Weiner, 1985). Two individuals might thus appraise the same event quite differently and experience very different emotions due to their disparate needs and goals, as happens when one student complains 
about a professor's inappropriately critical comments on a term paper while a more appreciative student striving for improvement interprets the same comments as helpful feedback. Another example of a top-down approach to emotion is the hypothesized role of affective memories, whereby previous affective reactions are triggered when that stimulus is encountered again (Fiske, 1982; Fiske \& Pavelchak, 1986; Forgas, 1992; Hoffman, 1986; Leventhal, 1980, 1984; Zajonc, Pietromonaco, \& Bargh, 1982). In addition, clinical researchers have demonstrated that people's expectations about the effectiveness of therapeutic techniques influence the extent to which these techniques alter their affective states (e.g., their fear of snakes; see Kirsch, 1985; Kirsch, Tennen, Wickless, Saccone, \& Cody, 1983).

Similar to these top-down approaches to the study of emotion, we argue that affective experience is profitably viewed as the interplay between knowledge structures and actual experiences. Our focus, however, is on a type of knowledge structure that has received little attention: People's expectations about their affective experiences. Our previous work has indicated that affective expectations can exert a powerful effect on actual affective experiences, even when the objective experience is inconsistent with the expectations (Wilson \& Klaaren, 1992; Wilson, Lisle, Kraft, \& Wetzel, 1989). For example, in one study subjects looked at single-panel cartoons, with the expectation that the cartoons would be funny. Compared to a control group who had no expectations, these subjects rated the cartoons as significantly funnier, and laughed and smiled more at the cartoons. In addition, they took significantly less time to rate them. This latter finding is consistent with the hypothesis that when people have an affective expectation, they perform rapid "confirmation checks" of their actual experiences. If these checks do not reveal any large discrepancies between their experiences and their expectations, people assume that their expectations have been confirmed.

The present studies focused on the effects of affective expectations on people's recollections of their prior affective experiences and their willingness to repeat these experiences. After an event is over, to what extent do our original affective expectations color our memories of how pleasant the event was? We tested the hypothesis that affective expectations do exert such an effect, and that such an effect can be problematic. If affective expectations cause us to misremember an unpleasant experience as being more pleasant than it was, for example, we might make ill-advised decisions based on biased memories or perceptions. Like Jared Diamond, we might commit ourselves to reliving a supposedly pleasant experience, only to rediscover the leeches, fever, and diarrhea.

There are a number of ways in which affective expectations could 
influence people's willingness to repeat an activity. First, it is possible that expectations influence how enjoyable an activity is at the time we perform it (as we have found in our past studies), and that this distortion leads to people's increased willingness to repeat the activity later. That is, affective expectations may exert their effect only at the time people initially experience an activity, by causing people to put a spin on their experiences that is consistent with their expectations. If we expect to enjoy an activity that turns out to have negative features, we pay less attention to these negative features or weight them less, thereby increasing our enjoyment and making us more likely to want to repeat the activity again. According to this initial effects hypothesis, affective expectations do not have any additional effect as time passes. They influence people's initial enjoyment, which then influences later decisions about whether to repeat the event.

Alternatively, affective expectations might continue to exert an effect over time by influencing people's memories for the activity. People's memories could be influenced in two ways. According to the reinterpretation hypothesis, as time passes people reinterpret aspects of the experience that conflicted with their affective expectations to be more in line with their expectations, such that they are more likely to behave consistently with their expectations. This reinterpretation could involve either a change in meaning of an experience (e.g., what seemed annoying at the time now seems amusing), or a change in weighting of an experience (e.g., an experience still seems annoying, but is viewed as less consequential). For example, after Jared Diamond visited the Lakes Plain he remembered the leech bites and diarrhea, but he seems to have assigned less weight to these negative experiences due to his positive expectations. It may be that when people are deciding whether to repeat an activity, they normally base that decision on their recall of how enjoyable it was. If the original experience was discrepant with their expectation, however, they may decide to weight the inconsistent aspects of the experience lesseven though they can recall them.

It may be, however, that affective expectations have a more dramatic effect on memory. According to the selective memory hypothesis, expectations act as a filter on people's memories for past events, such that they are less likely to remember aspects of the event that conflicted with their expectations or more likely to remember consistent events. This view is consistent with research indicating that people's schemas often influence their recall of events, such that people are (at least under some conditions) more likely to remember schema-consistent material (e.g., Higgins, King, \& Mavin, 1982; Stangor \& Ruble, 1989; Wyer, Bodenhausen, $\&$ Srull, 1984). If such a process operates in the realm of affective expectations, then people's decisions about whether to repeat an activity 
may be more a function of their original expectations than the objective nature of the event.

We should note that these different hypotheses about the role of expectations are not exclusive; it is possible that all three operate simultaneously. For example, it is possible that positive expectations influence people's decisions to repeat an activity by making an experience seem more pleasant as it is occurring and influence memory by causing some inconsistent memories to be weighted less and others to be forgotten. The main goal of the present studies was to demonstrate that affective expectations can influence people's recollections of their prior affective experiences and their willingness to repeat these experiences, rather than presenting definitive evidence about which of the three hypotheses we have offered is most accurate. Nonetheless, we will present evidence (in Study 2) that implicates one of these hypotheses more than the others.

We first examined the role of affective expectations on a real-world experience of some importance to college students, their winter vacations. We hypothesized that when people recalled how much they enjoyed their vacation, they would be influenced by their original expectations about how enjoyable it would be as well as their recall of how pleasurable their specific experiences during the vacation were. Study 1 employed a correlational design, which limits the causal conclusions we can draw. Study 2 was a laboratory experiment in which we manipulated people's affective expectations and the quality of their actual experiences.

\section{STUDY 1}

\section{OVERVIEW}

We capitalized on the fact that many students look forward to their winter vacations with high expectations that may or may not be fulfilled. Students' affective expectations regarding their upcoming winter vacation were assessed during the last two weeks of fall semester classes. At the beginning of the next semester we assessed their actual experiences during their vacation, as well as their overall evaluation of the vacation. We hypothesized that people's original affective expectations would have a substantial effect on their overall evaluations of the vacation.

\section{METHOD}

\section{Subjects}

Subjects were students enrolled in introductory psychology and social psychology classes at the University of Virginia. Participation was vol- 
untary. One hundred and fifty-seven subjects filled out the first questionnaire. After repeated attempts, we were able to collect posttest data for 124 (78 females, 46 males) of these subjects, which constituted our final sample.

\section{Procedure}

Affective Expectations. During the last two weeks of classes before winter vacation, we asked participants how good they thought their vacation would be $(1=b a d, 10=$ good $)$, how relaxing they thought it would be $(1=$ not relaxing, $10=$ very relaxing $)$, how much they thought they would enjoy it $(1=$ not enjoy much, $10=$ enjoy a lot $)$, and how excited they were about it $(1=$ not very excited, $10=$ very excited $)$. Participants also rated their current semester on three dimensions-academic difficulty, stress level, and emotional and personal well-being, as well as some additional questions about their travel plans (destination and purpose) and which family members they would see.

An additional group of 19 subjects (randomly assigned) answered all questions except the ones asking for their affective expectations about their vacation. The reason these subjects were included was to assess whether asking people to make predictions about their vacation influenced how they experienced their vacation (Sherman, 1980). At Time 2, no differences were found between the reports of this group and those who did make predictions. Thus, the results of those who did not make predictions about the quality of their vacation will not be discussed further.

Post-Vacation Ratings. Subjects were called by research assistants who claimed to be a graduate student working on her master's thesis on "family and leisure traditions in America." The first questionnaire was not mentioned. Only one subject asked if there was a connection, suggesting that there was not a strong demand to appear consistent with their earlier ratings. Subjects were called either 1 or 6 weeks after they returned from winter vacation. Whether they were called after 1 or 6 weeks had no significant effects on people's ratings, thus we will not discuss this variable further.

The research assistants asked subjects two sets of questions, the order of which was counterbalanced. One set of questions assessed global satisfaction with winter vacation: how good people thought their vacation was, how relaxing it had been, and how much they had enjoyed it, again on 10-point scales. The other set consisted of nine yes-no questions asking about specific aspects of people's vacation: whether they had felt compelled to go to any holiday or religious gatherings that they would have preferred not to attend, whether they got to do everything they 
wanted to do, whether it was stressful being with their families, whether their travels had gone smoothly, whether they had trouble adjusting to the rules at home, whether they got to relax as much as they wanted to, whether the weather was okay, whether they enjoyed getting together with hometown friends, and whether there were any other additional positive or negative aspects of their vacation. The order of the first eight of these questions was counterbalanced according to a latin square design; the question probing for additional information always came last in the set.

\section{RESULTS AND DISCUSSION}

Initial analyses revealed no significant effects of gender or of the order in which we asked the post-vacation questions, thus we collapsed across these variables in all subsequent analyses. Subjects' scores on the questions about their affective experiences (how good they expected their vacations to be, how much they expected to enjoy them and how excited they were about them) at Time 1 were highly correlated, average $r=.81 .{ }^{1}$ A mean score of these three measures was computed and used as an index of subjects' expectations about their vacation. Similarly, at Time 2, a mean was computed for subjects' scores of how good their vacations were and how much they enjoyed them (these two measures correlated .77).

A composite score was also computed from the nine dichotomous questions asking subjects about specific aspects of their vacation. For each aspect that subjects indicated was a positive part of vacation (e.g., they answered "yes" to the question "Was the weather okay?" or they answered "no" to the question "Was it stressful having family members together?"), one point was added to this composite score. For each aspect that subjects indicated was a negative part of vacation (e.g., they answered "no" to the question "Did your travels go smoothly?"), one point was subtracted from this composite score. Included in this measure were responses to our open-ended question about any additional positive or negative experiences people had during their vacation: If subjects mentioned an additional positive experience, one point was added to the

1. The fourth measure of expectations at Time 1, how relaxing subjects thought their breaks would be, was not as highly intercorrelated with the three affective measures. Furthermore, a factor-analysis of the four Time 1 expectation measures using a one-factor model indicated that the loading for the "relax" variable on the single factor was significantly smaller than for the other three variables. Therefore, we did not include the "relax" variable in our Time 1 measure of expectations, nor did we include subjects' responses to the question about how relaxing their vacations had been at Time 2 in their Tỉme 2 global ratings of their vacations. 
composite score; if they mentioned an additional negative experience, one point was subtracted.

The main hypotheses were tested by regressing subjects' overall ratings of their vacation at Time 2 on their Time 1 expectations about their vacation and the specific experiences they encountered during their vacation. The $R^{2}$ for the regression was $.38, F(2,121)=37.20, p<.0001{ }^{2}$ Both of the predictor variables accounted for a significant amount of the variance in people's ratings of how much they enjoyed their vacation. The beta for Time 1 expectations was $.51(t=7.10, p<.0001)$, and the beta for specific experiences was $.27(t=3.79, p<.0002)$. Thus, interestingly, people's affective ratings of their vacation were predicted not only by their ratings of their actual experiences during the vacation but also by their original affective expectations.

It is interesting to note that the correlation between people's expectations about their vacation and their specific experiences was not significant, $r=.15$. People's expectations appear to have colored their global enjoyment of their vacation, without changing their evaluations of their specific experiences. In addition, we should note that peoples' fall semester ratings of academic difficulty, stress level, and emotional and personal well-being were not predictive of either expectations for vacation or ratings of the actual experience.

It is possible that we obscured the contributions of specific experiences by using a composite score. Perhaps there were one or two key experiences that accounted for a great deal of the variance of people's evaluations of their vacations, but these contributions were diluted by averaging them with experiences that mattered little. To test this possibility, we replaced the composite measure with the individual measures of experience in a series of separate regression analyses. For example, one such regression included whether it was stressful for subjects to be with their families as one predictor variable, and the expectation measure as the other. Only two of the specific experiences were significant at the .05 level by themselves--whether subjects were able to do all that they planned, beta $=.18, t=2.45, p<.02$ (subjects who got to do all they planned enjoyed their vacations more), and whether they got to relax as much as they had wanted, beta $=.19, t=2.60, p<.02$ (subjects who got to relax as much as they wanted had better vacations). However, in these and all other cases the beta weights for the specific experiences were significantly smaller than the beta weight for affective expectations (Cohen \& Cohen, 1983).

2. No interactions or curvilinear effects were hypothesized. When interaction and curvilinear terms were added to the regression, they were not significant and did not significantly change the $R^{2}$. 
To summarize, both knowing people's affective expectations about their winter vacation and knowing people's accounts of their specific experiences during the vacation were helpful in predicting their overall evaluation of the vacation. The significant effect of expectations as well as experiences is particularly interesting given that people's expectations were measured several weeks earlier whereas their ratings of specific experiences were made at the same time as their ratings of their overall evaluation. In some cases, people rated the quality of their specific experiences immediately before rating the overall quality of their vacation (that is, as mentioned earlier, we counterbalanced the order of the questions at Time 2). Nonetheless, both affective expectations and ratings of specific experiences were significant predictors of people's overall evaluations.

Study 1 was, of course, a correlational study. This method had the advantage of enabling us to test our hypotheses in a real-world setting, but made it impossible to assign people randomly to expectation or experience conditions. Thus, we cannot rule out the possibility that some third variable such as overall optimism or enthusiasm is responsible for positive expectations before the vacation began as well as positive evaluations of the vacation after it was over. Further, it is possible that the specific aspects of people's vacation tapped by our composite measure may not have been the crucial ones that influence quality of the vacation. There could be other important determinants which we neglected to assess, such as what students received as holiday gifts, or whether they got to spend time with a girlfriend or boyfriend, that are the real key to how good students' vacations are. We did attempt to assess such factors in our open-ended question, wherein people listed additional positive and negative experiences during their vacation. Some people, however, may not have made the effort to describe additional experiences, or they may have been reluctant to describe experiences for social desirability reasons. A final drawback to this first study is the fact that the affective expectations were measured on similar scales as the overall enjoyment measure, allowing for the possibility that the greater effect of expectations could be partially attributable to shared method variance.

To address these interpretational problems, we manipulated people's expectations and experiences experimentally in Study 2. In addition, we extended our investigation to the question of whether affective expectations influence people's decisions about whether to repeat an activity. This question is particularly interesting in the case whereby people expected to enjoy an activity, but the activity turned out to be unpleasant. To what extent will their expectations versus their actual experiences dictate their decision about whether to engage in the activity again? 


\section{STUDY 2}

\section{OVERVIEW}

We telephoned subjects before they participated in the study. We told people in the positive expectation condition that the experimental session would be enjoyable, whereas we did not say anything about how enjoyable the study would be to people in the neutral expectation condition. Cross-cutting this expectation manipulation, we made the experimental session more enjoyable for some people than others. In the positive experience condition people watched a movie under relatively pleasant conditions. In the negative experience condition people had to place their head on a chin rest and watch the film from an awkward angle while seated in an uncomfortable chair. Thus, we manipulated people's affective expectations and the objective pleasantness of the experimental session in a $2 \times 2$ design. The chief dependent measure was subjects' willingness to participate in the study again, when telephoned 3-4 weeks later.

\section{METHOD}

\section{Subjects}

Subjects were 90 students (46 males, 44 females) at the University of Virginia. A research assistant randomly selected names from a list of all students enrolled in introductory psychology, and telephoned these people to see if they were willing to participate in return for course credit. Four people were eliminated from the analyses because they had already seen the movie shown in the experimental session. Four additional people were eliminated because they could not be contacted to ask the follow-up questions. The results are very similar if these eight subjects are included in the analyses for which they have data, and are actually slightly more reliable in most cases.

\section{Procedure}

Manipulation of Affective Expectations. If a student agreed to participate (and virtually all who still needed the class credit did), the research assistant gave him or her directions to the research labs. She then randomly assigned the student to the positive or neutral expectation condition. In the positive expectation condition she said,

Let me tell you a little more about the study. You are going to watch a really neat movie that everyone likes a lot. All you have to do is watch the movie and answer a few questions. It's really easy and fun. In fact, it's not even like being in an 
experiment, it is like going to the movies. Other people who have done it have really liked it.

In the neutral expectation condition the assistant simply said "We'll tell you more about the study when you get there." Most participants took part 2 days after this initial phone contact, though the interval ranged from 1 to 5 days.

People were seen individually by an experimenter who was unaware of people's expectation condition. She handed out written instructions explaining that the study was concerned with the psychology of film appreciation. "Right now we are in the pretesting stage," the instructions explained, "where we are just asking students to make some ratings of various movies." People in the positive expectation then read that, "In this study you will watch a movie that lasts about 20 minutes. As we told you on the phone, this is a very popular movie that has won several awards, and is very popular among students." People in the neutral expectation condition did not receive these sentences. All participants were told that they would watch a movie on a video recording system by themselves, and that when it was done they would answer some questions about the movie on an anonymous questionnaire.

The experimenter then handed subjects a copy of the questionnaire that they would be filling out, ostensibly to familiarize them with the kinds of questions they would be asked. She said, "Here is a copy of the questionnaire that was just lying around. I think it's left over from someone who did the study before you came; I'm not sure." In the neutral expectation condition the questionnaire was blank. In the positive expectation condition the questions were answered, and it was clear that the previous participant had thoroughly enjoyed the movie and the experiment as a whole (on nine-point scales, the answers were either 8 or 9). Thus, we created positive expectations by telling people over the phone that the study was enjoyable, telling them this again in the written instructions, and allowing them to see that a previous participant had enjoyed the experiment. Because the questionnaire had an opaque cover sheet, the experimenter remained unaware of people's expectation condition. The experimenter left the room while the subject looked through the questionnaire and completed a consent form.

Manipulation of the Objective Experience. We also manipulated how enjoyable the experiment was objectively. In the positive experience condition people were seated in a comfortable chair and allowed to adjust the volume of the monitor and the room lights to their liking. In the negative experience condition, the initial instructions said that one purpose of the study was to see if the angle at which people view the television monitor influences what they think of the film. People were 
seated on an uncomfortable chair at a 45 degree angle from the screen, and were asked to place their chin on a foam pad attached to a camera tripod (ostensibly to keep the viewing angle constant). They were allowed to adjust the tripod to a comfortable height, but were told that it was important to keep their head in the same position for the entire film. Further, they watched a copy of the film that had been re-recorded several times, such that the picture quality was poor. In addition, the experimenter adjusted the monitor such that the screen was unpleasantly bright and left the room lights on at their brightest setting. Finally, she left the volume at a low setting.

All participants watched Charlie Chaplin's film The Immigrant, which lasted 20 minutes. When the movie was over the experimenter gave people a questionnaire, and asked them to place it in a box containing other questionnaires when they were done to ensure that people's responses were anonymous. The first five questions concerned people's enjoyment of the film and the experiment, all answered on 9-point scales. People rated how much they enjoyed the study overall $(1=$ not at all, $9=$ very much), how much they enjoyed watching the movie $(1=$ not at all, 9 $=$ very much $)$, how funny they thought the movie was $(1=$ not at all, $9=$ very funny), how pleasant an experience it was to be in the study $(1=$ not at all pleasant, $9=$ extremely pleasant), and how much they would like to participate in a study like this again $(1=$ not at all, $9=$ very much $)$. The next set of questions included fillers that were consistent with the cover story (e.g., what their favorite movies were, whether they owned a video tape recorder. ), and three checks on the expectation manipulation. These latter quesłions asked how much they thought they would enjoy the study before they arrived, how much they thought they would enjoy the study "after you came today and the study was explained to you, but before the movie came on," and how much they thought they would enjoy the study "at the point where the movie came on and you realized what kind of movie it was." Again, participants answered all of these questions on 9-point scales $(1=$ not at all, $9=$ very $m u c h)$. When participants completed the questionnaire the experimenter gave them a written description of the study that repeated the initial explanation of the study as one concerned with the psychology of film appreciation (i.e., people were not told the true purpose of the study at this time). Before the participants left, the experimenter urged them not to discuss the study with their classmates.

Follow-Up Phone Call. Three to four weeks after people participated in the movie-viewing session, a different research assistant, who was unaware of subjects' experimental condition, telephoned participants. To minimize demand characteristics, she emphasized that she was a different assistant than the one who had first called them or conducted the experimental session. She then asked the following question: 
First, we are thinking of having people do the experiment again. The study would be exactly the same, except that you would see a different Charlie Chaplin movie. Everything else about the study would be identical. Right now we are trying to find out how willing people would be to do the study again. We would be paying people this time. Could you tell me how interested you would be in doing it again on a scale that ranged from 1 to 10 , with $1=$ "not at all interested," and $10=$ "very interested?"

She then said that "we are trying to get a true indication of how much people enjoyed being in our experiment," and asked people to rate their enjoyment from $1-10$, with $1=$ not all enjoyable and $10=$ very enjoyable. Finally, she asked people to "think back to when you did our study before," and to describe both what they liked and disliked about the study. The assistant noted whether they listed something positive or negative, and the order in which these memories were mentioned. ${ }^{3}$ She then thanked people and said that she would call them back if their participation was needed. At the end of the semester we mailed all participants a complete explanation of the experiment and its true purpose.

\section{RESULTS AND DISCUSSION}

Initial analyses revealed that there were no significant effects involving gender, thus we collapsed across this variable in all subsequent analyses.

Manipulation Checks. The three questions concerning how much people expected to enjoy the experiment were moderately intercorrelated (Cronbach's alpha $=.46$ ). A 2 (expectation manipulation: positive vs. neutral) $\times 2$ (experience manipulation: positive vs. negative) analysis of variance (ANOVA) on the means of these three items revealed only a main effect of the expectation manipulation, $F(1,78)=6.66, p<.05$. People with positive expectations indicated that they expected to enjoy the study more than did people with neutral expectations, $M s=6.24$ and 5.58 , respectively. 4

3. We should note two things about the follow-up. First, we initially asked people an additional question, namely how much they would like to be paid if they agreed to do the study again. Because responses to this question were extremely variable, and did not vary significantly by condition, we stopped asking it after the first 39 participants. Second, toward the end of the experiment we decided to vary the order in which the questions were asked. For most of the experiment, the order of questions was whether people were willing to participate again, how much they had enjoyed the study, and the recall questions. Twenty-two of the last participants were randomly assigned to a condition in which they first answered the recall questions, then whether they were willing to participate again and how much they had enjoyed the study. There were no significant effects of this order manipulation, thus we collapsed across it in all subsequent analyses. 
Enjoyment at the Time of the Experimental Session. Because people's responses to the five questions about their enjoyment of the study and the film were highly intercorrelated (Cronbach's alpha $=.92$ ), we averaged their responses to these questions. A $2 \times 2$ ANOVA on this index revealed that people's enjoyment was affected by both the expectation and the experience manipulations. The main effect of expectations was significant, $F(1,78)=5.05, p<.05$, reflecting the fact that people with positive expectations enjoyed the study more than did people with neutral expectations, $M s=6.86$ and 6.21 , respectively. Thus, consistent with previous studies, people's affective expectations about an experience influenced their actual enjoyment of that experience (Wilson et al., 1989). The main effect of the experience manipulation was also significant, $F(1,78)=9.54, p<.01$, reflecting the fact that people who saw the film under pleasant conditions enjoyed the experiment more than people who saw the film under unpleasant conditions, $M s=7.07$ and 6.10 , respectively. The interaction between expectations and experience was not significant, $F(1,78)<1$ (see individual cell means in Table 1$)^{5}$

Follow-up Phone Call Measures. Our key measure was people's willingness, at the time of the follow-up phone call, to participate in the study again. Results for this measure indicated that people's affective expectations were a reliable determinant of people's willingness to repeat the study, whereas the objective pleasantness of the experience was not. A $2 \times 2$ ANOVA revealed a significant main effect of expectations, $F(1,78)$ $=6.97, p=.01$, reflecting the fact that people in the positive expectation condition were more willing to repeat the study, $M=8.08$, than people in the negative expectation condition, $M=6.81$. Neither the main effect of the objective experience manipulation nor the interaction were significant, Fs $<1$ (see cell means in Table 1).

As noted earlier, there are at least three ways in which people's expectations could have influenced their willingness to repeat the experiment. First, this effect might have been due solely to the influence of

4. Because this index had a relatively low alpha, we also analyzed the three manipulation check questions separately. There was a significant main effect of the expectation manipulation on two of them: How much people expected to enjoy the study before arriving and how much they expected to like it at the point when the movie first came on. There were no significant effects on the question about how much people expected to enjoy the movie after they arrived but before the movie came on.

5. It is possible that our expectation manipulation did not affect subjects' true experience of the movie, but rather just affected how subjects reported that movie-viewing experience. This explanation based on demand characteristics is a possibility, but it is important to note that all ratings were made anonymously, thereby reducing demand pressures. Further, previously mentioned work by Wilson et al. (1989) shows that expectations influence not only self-reports but also actual behaviors, even when subjects are unaware that their behavior is being observed. 
TABLE 1. Mean Expectation, Enjoyment, and Willingness Scores by Condition

\begin{tabular}{|c|c|c|c|c|}
\hline \multirow[b]{2}{*}{ Variable } & \multicolumn{2}{|c|}{ Positive Expectation } & \multicolumn{2}{|c|}{ Neutral Expectation } \\
\hline & $\begin{array}{c}\text { Positive } \\
\text { Experience }\end{array}$ & $\begin{array}{c}\text { Negative } \\
\text { Experience }\end{array}$ & $\begin{array}{c}\text { Positive } \\
\text { Experience }\end{array}$ & $\begin{array}{c}\text { Negative } \\
\text { Experience }\end{array}$ \\
\hline \multicolumn{5}{|l|}{ Time 1} \\
\hline Expectation Manipulation Check ${ }^{a}$ & 6.58 & 6.03 & 5.68 & 5.48 \\
\hline Enjoyment of Study & 7.57 & 6.42 & 6.70 & 5.75 \\
\hline \multicolumn{5}{|l|}{ Time 2} \\
\hline Willingness to Participate Again ${ }^{b}$ & 8.60 & 7.75 & 6.90 & 6.73 \\
\hline Enjoyment of Study ${ }^{b}$ & 8.40 & 7.25 & 7.52 & 6.45 \\
\hline
\end{tabular}

${ }^{a}$ Rated on 9-point scales, with higher numbers representing more positive expectations and more enjoyment.

${ }^{b}$ Rated on 10-point scales, with higher numbers representing more of a willingness to participate again and more enjoyment.

people's expectations on their initial enjoyment of the study. That is, expectations increased enjoyment during the actual experiment, and people's recall of this increased enjoyment could have increased their willingness to repeat the experiment (the initial effects hypothesis). Second, people's expectations might have caused people to reinterpret or change their weightings of expectation-inconsistent events (the reinterpretation hypothesis). Third, people's expectations might have caused people to forget events that conflicted with their expectations (the selective memory hypothesis).

Our data are inconsistent with the third interpretation, that people's expectations led to selective memory in an expectation-consistent manner. People in the negative experience condition could retrieve the fact that there were unpleasant aspects to the experiment, even when they had positive expectations. Evidence for this point comes from our measure of people's recollections about the study, which we assessed by subtracting the number of negative aspects they recalled from the number of positive aspects. A 2 (Expectation manipulation) $\times 2$ (Experience manipulation) ANOVA revealed a significant effect of Experiençe, $F(1$, $78)=16.78, p<.001$, reflecting the fact that the people in the positive experience condition remembered more positive aspects and fewer negative aspects of the study than did people in the negative experience condition (see Figure 1). The main effect of the expectation manipulation was not significant, $F<1$.

Interestingly, there was also a nearly-significant interaction, $F(1,78)=$ $3.08, p=.08$. As seen in Figure 1, a positive expectation increased recall for positive aspects of the study in the positive experience condition, but decreased recall for positive aspects of the study in the negative experience condition. This result is clearly at odds with the selective memory interpretation. When people's expectation conflicted with their experience (the negative experience-positive expectation cell), people had 
better, not worse recall for expectation-inconsistent events. This finding may reflect the tendency to think about and elaborate upon information that conflicts with an expectation-a finding that is well-established in the impression formation literature (e.g., Hastie, 1980; Srull, 1981). Enhanced memory for expectation-inconsistent events is especially likely to occur when people's expectations are not well-developed (Stangor \& Ruble, 1989), as was the case in the present study (i.e., people had little experience with the experimental setting). ${ }^{6}$

Further evidence against the selective memory hypothesis comes from people's ratings, made during the follow-up phone call, of how enjoyable the study had been. If expectations distorted people's memories, we might expect the effects of expectations on people's recollections of how enjoyable the study was to increase over time (as expectation-inconsistent aspects of the study were forgotten). To see if this was the case, we performed a 2 (Expectations, positive vs. neutral) $\times 2$ (Experience, positive vs. negative) $\times 2$ (Time, enjoyment rated at the experimental session vs. during the follow-up phone call) ANOVA, with the last factor treated as a repeated measure. (Because enjoyment was assessed on different scales at the two times, we first converted them to standard scores.) Contrary to the selective memory hypothesis the effects of expectations did not increase over time: The Expectation by Time interaction was not significant, $F<1$. The only significant findings were a main effect of Experience, $F(1,78)=13.62, p<.001$, and a main effect of Expectations, $F(1,78)=7.46, p<.01$. Thus, people's initial enjoyment of the study was influenced by both their expectations and the objective nature of the experience (as reported earlier), and these effects persisted over time, without decreasing or increasing in magnitude (see Table 1 for cell means). This result is consistent with Study 1, in that people's overall ratings of an experience were influenced by both their affective expectations and the objective positivity of the event. It was not the case that the aspects that were inconsistent with people's expectations were forgotten.

The fact that the effects of expectations on recollections of enjoyment did not increase over time might be seen as support for the initial effects hypothesis, which says that the effects of expectations at Time 2 are

6. We also examined separately the number of positive and negative aspects of the study people recalled. The interaction shown in Figure 1 was strongest on positive recollections, and in fact was significant on this measure but not on the measure of negative recollections. These results suggest that selective memory did occur when people's experiences were consistent with their expectations, in that people in the positive expectation-positive experience condition recalled the most positive aspects of the study. However, people in the positive expectation-negative experience condition recalled the fewest positive aspects of the study, suggesting that when expectations were violated people did not engage in selective memory for expectation-consistent events. 


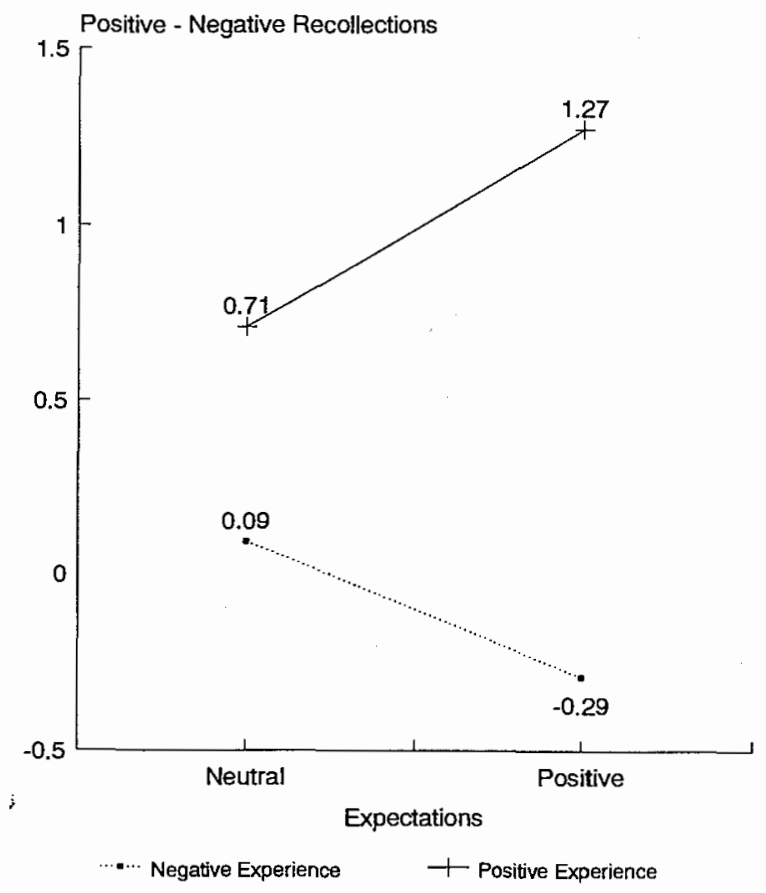

FIGURE 1. Effects of affective expectations and objective experiences on people's recall for the experiment. The dependent measure is the number of positive aspects of the study people recalled minus the number of negative aspects.

accountable solely by their effects at Time 1 . However, this finding does not rule out the possibility that memory distortions add to the effects over time. This possibility arises when we consider that any initial effect of expectations might be expected to decay over time as people's recollections about how much they enjoyed the study faded. The fact that no such decay was found thus suggests that the effects of people's expectations may have been "boosted" by expectation-consistent memory distortion as time passed, creating a consistent pattern over time. Of course, the time delay in the present study may simply have been too brief to find a decay in the initial effects of expectations, but the fact that no decay was found is at least suggestive of the fact that other processes were operating.

A more direct test of the initial effects hypothesis would be to see if people's willingness to repeat the experiment is accounted for solely by their ratings of how much they enjoyed the study at the time of the experiment. To find out, we performed an analysis of covariance on people's willingness to repeat the experiment, using their ratings of 
initial enjoyment as the covariate. If people based their decision to repeat the activity on their initial enjoyment (which was colored by their expectations), then there should be a significant effect of the covariate (that is, people's initial enjoyment should correlate with their willingness to do the study again). The covariate was, in fact, significant, $F(1,77)=$ $4.22, p<.05$. The analysis of covariance, however, also allows us to test whether adjusting for people's initial enjoyment eliminates the effects of people's expectations. According to the initial effects hypothesis it should, because the expectation effect is said to be mediated solely by its effect on initial enjoyment. However, we found that the expectation main effect remained significant, $F(1,77)=4.43, p<.05$ after adjusting for initial enjoyment, suggesting that expectations exerted a significant effect beyond that accounted for by people's initial enjoyment.'

We suggest that expectations exerted this significant effect in a manner akin to our reinterpretation hypothesis. That is, we suggest people whose expectations were violated reinterpreted those aspects of the experience that were inconsistent with their expectations. This reinterpretation would then make these people's decision to repeat the experiment less predictable from their initial ratings of how much they enjoyed the study because, at the time of the follow-up phone call, they presumably discounted aspects of their initial experiences that were inconsistent with their expectations. Thus, when people's expectations were consistent with their actual experiences, they were likely to use their initial enjoyment to guide their decisions about whether to repeat the experience. When there were discrepancies between people's expectations and the actual experience, however, people may have discounted or reinterpreted this initial enjoyment, viewing it as an aberration or as an atypical experience. They may thus have relied more on their affective expectations than their initial enjoyment to guide their decision about whether to repeat the experience.

If this view is correct, then the correlation between initial enjoyment and willingness to repeat the experiment should be especially low among those who had the largest mismatch between their expectations and actual experiences. Consistent with this reasoning, the correlation was lowest in the "mismatch" cell (the positive expectations-negative experience condition), $r(22)=-.09, n s$, and relatively high in the other three conditions, $r \mathrm{~s}$ between .29 and .52 . A contrast testing the prediction

7. It is possible that error in measurement of a covariate can cause an analysis of covariance (ANCOVA) to underadjust for initial differences on the covariate. Fortunately, however, our covariate (people's initial enjoyment of the movie) was highly reliable, with an alpha of 92 . The results of the ANCOVA were virtually identical when we corrected for measurement error (Huitema, 1980). 
that the former correlation was lower than the other three was nearly significant, $z=1.87, p=.06^{8}$

We should note, however, that other analyses were not as consistent with the reinterpretation hypothesis. For example, if people in the "mismatch" cell viewed their initial enjoyment as an atypical experience and based their decision to repeat the activity more on their affective expectations, then we might expect their willingness to repeat the activity to be more correlated with their affective expectations (as assessed by our manipulation checks) than in other cells. In fact, there were no significant differences in these correlations between the four cells of the design. All of the correlations were low (less than or equal to $.32, n s$ ), possibly indicating a lack of reliability of our measures or problems with restriction of range. Nonetheless, it should be recalled that in the analysis of variance, our manipulation of affective expectations did exert a significant effect on people's willingness to repeat the activity.

To summarize, we found that people's willingness to repeat an activity was influenced by their affective expectations but not by the objective pleasantness of the experience. The selective memory hypothesis could not account for this result, because people in the positive expectationsnegative experience condition did not distort their memory in an expectation-consistent manner. (In fact, they were somewhat more likely to remember aspects of the experience that were inconsistent with their expectations.) Nor was the initial effects hypothesis supported, in that the expectation manipulation significantly influenced people's willingness to repeat the experiment, even after adjusting for people's initial enjoyment. Some evidence for the reinterpretation hypothesis-that people discount or reweigh memories of expectation-inconsistent events-was found, though clearly such an explanation needs to be explored further in subsequent research.

\section{GENERAL DISCUSSION}

Not surprisingly, we found that people's later evaluations of an experience were influenced by their reports about how enjoyable the experience had been. In Study 1, people's reports about how enjoyable their winter vacations had been were significantly related to their reports about the pleasantness of their actual experiences during the vacation.

8. These differences in correlations suggest that in the analysis of covariance reported earlier, the assumption of homogeneous covariate regression coefficients may have been violated. To test this we redid the analysis of covariance, including all of the factor $x$ covariate interaction terms in the model. None of these interactions were significant, though the Expectation $\times$ Covariate interaction approached significance, $F(1,74)=3.00, p$ $=.09$. 
Similarly, in Study 2, people's recollections about how enjoyable the movie-watching experiment had been were significantly affected by our manipulation of how pleasant the experiment was. More interestingly, people's retrospective reports of enjoyment were also significantly related to their original affective expectations about how enjoyable the experience would be, independently of how objectively pleasant it was.

Study 2 went beyond Study 1 by including a measure that is perhaps the most consequential to people: Their willingness to repeat the activity. When people actually had to decide whether to do the experiment again, their affective expectations influenced their choice, whereas the manipulation of the positivity of the experiment did not. Agreeing to watch a movie again under less than ideal viewing conditions is not as consequential as planning to return to a country where we will encounter leeches. Nonetheless, it is striking that people's decisions were influenced by affective expectations but not by the objective positivity of the experiment.

Earlier, we discussed the hypothesis that accounts for this finding the best, namely the idea that people with positive affective expectations discounted or reinterpreted experiences that were inconsistent with these expectations. Though not all of the findings were perfectly consistent with this interpretation, at present it seems to do the best job of accounting for the results.

We should note that the reinterpretation process we have discussed will not always lead to irrational or faulty decisions. If people's expectations remain in force when they relive an experience, these expectations might continue to color their reactions to it. For example, if people in Study 2 actually had come back to watch another Charlie Chaplin movie, those with positive expectations might well have enjoyed it more than those with neutral expectations, as they did at the original experimental session. However, people are not completely blind to expectation-inconsistent events, and if they base their decisions to relive an experience solely on their expectations, they might come to regret these decisions. At the original session of Study 2, for example, people were also influenced by the objective quality of the experience. It was not much fun to watch a movie of poor picture quality, from an awkward angle, in a brightly-lit room, while having to keep their head stationary on a tripod. It seems likely that if our subjects did repeat the study, those who had to endure these unpleasant conditions would not like it as much as those who did not-despite expectations to the contrary.

In this case the stakes are not particularly high. The worst scenario involves deciding to spend 20 minutes doing something that is somewhat unpleasant. Other real world situations may also involve relatively minor consequences. Yet there are situations in which there might be higher 
costs to basing decisions too much on one's affective expectations, such as planning to spend a substantial amount of money on a vacation, pouring all of your time and money into starting a new restaurant after one such venture had already failed, or going back to New Guinea to experience the leeches anew. In these cases especially, it would be to people's advantage to not let their affective expectations overpower their actual experiences when deciding whether they want to repeat an activity.

We should note that the present studies are limited in that they focused only on positive or neutral expectations. ${ }^{9}$ On the one hand negative expectations might, like positive expectations, lead people to discount or reinterpret discrepant experiences in line with the expectations, such that people who expected to dislike an activity are less likely to repeat it even if it had many positive features. This seems to be the logic behind people's reasoning when they tell us we disliked something only because we "never gave it a chance." Alternatively, the influence of negative expectations may not parallel that found for positive expectations. A contrast effect may occur in which people who are told a vacation or movie will be terrible actually end up liking it more than those with neutral expectations, if it has positive features. For example, one of the authors dreads going to professional conferences, but upon return, because nothing could be as bad as she imagined in advance, her memories of the meetings are tolerable. It may be that we are more motivated to relinquish our negative expectations than our positive ones so that we can experience positive rather than negative thoughts and feelings.

Although such contrast effects are certainly possible, Wilson et al. (1989) found no evidence for contrast on people's initial evaluations of an event among people with either positive or negative expectations. It may be that the conditions under which contrast effects occur have not been met in this type of research paradigm (e.g., people's expectations or the discrepancy between their expectations and their experiences may not have been large enough to create a contrast effect; Herr, 1986; Herr, Sherman, \& Fazio, 1983). Alternatively, it might simply be the case that contrast effects are rare in affective domains such as these, despite our intuitive notions (see Wilson \& Klaaren, 1992 for a further discussion of this issue).

It might also be argued that cognitive dissonance theory (Festinger, 1957) accounts for our results. It is possible that people were reluctant to admit to themselves that their positive expectations had been disconfir-

9. In Study 1 some individuals had negative expectations about their winter vacations, but there were not enough to allow a meaningful comparison between these participants and those who had positive expectations. Most participants had expectations that ranged from neutral to extremely positive. 
med in order to avoid the disappointment that might result from such an admission. Though we cannot completely rule out such an explanation, there are two sources of evidence against it. First, current theoretical perspectives and research on dissonance suggest that dissonance arises only when people freely act in ways that challenges their sense of morality or self-integrity (Thibodeau \& Aronson, 1992; Steele, Spencer, \& Lynch, 1993), and it is not clear that such conditions were met in the present studies. Discovering that an experiment is not as enjoyable as an experimenter told you it would be does not seem to represent much of a challenge to one's integrity.

Second, as mentioned earlier, Wilson et al. (1989) found that negative expectations operated similarly to positive expectations, in that people experienced events in ways that were consistent with these expectations. It would be difficult for a dissonance interpretation to explain why people would want to distort their experiences in ways that confirmed a negative expectation. Our more cognitive interpretation, that affective expectations act like schemas influencing people's interpretations of expectation-inconsistent events, seems to account for the findings better at this point.

We would like to emphasize that affective expectations are not the sole determinant of whether people wish to repeat an activity. Though we did not find an effect of the objective nature of the experience on people's decisions to repeat the experiment in Study 2, it is likely that, under other circumstances, there are such effects. For example, if people's experiences had been more discrepant from their expectations, these discrepant experiences may have stood out more. Further, a number of recent studies have examined other qualities of an experience, besides affective expectations, that determine people's liking for it (e.g., Fredrickson \& Kahneman, 1993; Hsee \& Abelson, 1991; Hsee, Abelson, \& Salovey, 1991; Kahneman, Fredrickson, Schreiber, \& Redelmeier, 1993; Varey and Kahneman, 1992). For example, Kahneman et al. (1993) found that people's decision about which of two painful events to repeat was a function not of the duration of the events, but of how unpleasant these events were at their worst moment and at their conclusion. In an interesting parallel to our results it appears that people are not unaware of differences in duration, nor do they forget about the duration of an event over time; nonetheless, duration is simply not very predictive of their later evaluations of the experience (Frederickson \& Kahneman, 1993).

Clearly, people's recollections of affective experiences are multidetermined and not a simple aggregate of their memories for all of the positive and negative aspects of these experiences. One interesting line of research would be to examine how people's affective expectations interact 
with or cancel out the influence of the peak and final experiences. In the meantime, it might be wise for people to concentrate on resurrecting specific memories of an actual experience-undistorted by their affective expectations-when deciding whether to repeat that activity, especially if they had positive expectations about an experience that turned out to be unpleasant. On the other hand, if the experience is a one-shot deal, our lasting memories for that experience might (under certain conditions) be enhanced by building up our positive expectations beforehand rather than trying to continually recount specific memories of the experience itself. Future progress on identifying precisely why and how our expectations can overwhelm our actual experiences could suggest further strategies for maintaining positive memories and evaluations of our experiences yet still managing to avoid repeating unpleasant activitiessuch as stinging ants and leeches.

\section{REFERENCES}

Cohen, J., \& Cohen, P. (1983). Applied multiple regression/correlation analysis for the behavioral sciences (2nd ed.). Hillsdale, NJ: Erlbaum.

Diamond, J. (1991, May). "Happiness in a hellhole." Discover, pp. 74-79.

Festinger, L. (1957). A theory of cognitive dissonance. Stanford, CA:Stanford University Press.

Fiske, S. T. (1982). Schema-triggered affect: Applications to social perception. In M. S. Clark \& S. T. Fiske (Eds.), Affect and cognition (pp. 55-78). Hillsdale, NJ: Erlbaum.

Fiske, S. T., \& Pavelchak, M. A. (1986). Category-based versus piecemeal-based affective responses. In R. M. Sorrentino \& E. T. Higgins (Eds.), Handbook of motivation and cognition: Foundations of social behavior (pp. 167-203). New York: Guilford.

Forgas, J. P. (1992). Affect in social judgments and decisions: A multiprocess model. In M. P. Zanna (Ed.), Advances in experimental social psychology (Vol. 25, pp. 227-275). San Diego, CA: Academic Press.

Fredrickson, B. L., \& Kahneman, D. (1993). Duration neglect in retrospective evaluations of affective episodes. Journal of Personality and Social Psychology, 65, 45-55.

Frijda, N. H. (1986). The emotions. Cambridge, England: Cambridge University Press.

Hastie, R. (1980). Memory for behavioral information that confirms or contradicts a personality impression. In R. Hastie, T. M. Ostrom, E. B. Ebbesen, R. S. Wyer, D. L. Hamilton, \& D. E. Carlston (Eds.), Person memory: The cognitive basis of social perception (pp. 141-172). Hillsdale, NJ: Erlbaum.

Herr, P. M. (1986). Consequences of priming: Judgment and behavior. Journal of Personality and Social Psychology, 51, 1106-1115.

Herr, P. M., Sherman, S. J., \& Fazio, R. H. (1983). On the consequences of priming: Assimilation and contrast effects. Journal of Experimental Social Psychology, 19, 323-340.

Higgins, E. T., King, G., \& Mavin, G. (1982). Individual construct accessibility and subjective impressions and recall. Journal of Personality and Social Psychology, 43, 35-47.

Hoffman, M. L. (1986). Affect, cognition, and motivation. In R. M. Sorrentino \& E. T. Higgins (Eds.), Handbook of motivation and cognition (pp. 244-280). New York: Guilford.

Hsee, C. K., \& Abelson, R. P. (1991). Velocity relation: Satisfaction as a function of the first 
derivative of outcome over time. Journal of Personality and Social Psychology, 60, 341-347.

Hsee, C. K., Abelson, R. P., \& Salovey, P. (1991). The relative weighting of position and velocity in satisfaction. Psychological Science, 2, 263-266.

Huitema, B. E. (1980). The analysis of covariance and alternatives. New York: Wiley.

Kahneman, D., Fredrickson, B. L., Schreiber, C. A., \& Redelmeier, D. A. (1993). When more pain is preferred to less: Adding a better end. Psychological Srience, 4, 401-405.

Kirsch, I. (1985). Response expectancy as a determinant of experience and behavior. American Psychologist, 40, 1189-1202.

Kirsch, I, Tennen, H., Wickless, C., Saccone, A. J, \& Cody, S. (1983). The role of expectancy in fear reduction. Behavior Therapy, 14, 520-533.

Leventhal, H. (1980). Toward a comprehensive theory of emotion. In L. Berkowitz (Ed.), Advances in experimental social psychology (Vol. 13, pp. 139-207). New York: Academic Press.

Leventhal, H. (1984). A perceptual-motor theory of emotion. In L. Berkowitz (Ed.), Advances in experimental social psychology (Vol. 13, pp, 139-207). New York: Academic Press.

Ortony, A., Clore, G, L., \& Collins, A. (1988). The cognitive structure of emotions. New York: Cambridge University Press.

Roseman, I. J. (1984). Cognitive determinants of emotion: A structural theory. In P. Shaver (Ed.), Reviezu of personality and social psychology: Emotions, relationships, and health (Vol, 5, pp. 11-36). Beverly Hills, CA: Sage.

Shaver, P., Schwartz, J, Kirson, D., \& O'Connor, C. (1987). Emotion knowledge: Further exploration of a prototype approach. Journal of Personality and Social Psychology, 52, 1061-1086.

Sherman, S. J. (1980). On the self-erasing nature of errors of prediction. Journal of Personality and Social Psychology, 39, 211-221.

Smith, C. A., \& Pope, L. K. (1992). Appraisal and emotion: The interactional contributions of dispositional and situational factors. In M. S. Clark (Ed.), Revierv of personality and social psychology: Emotion and social behavior (Vol. 14, pp. 32-62). Newbury Park, CA: Sage

Srull, T. K. (1981). Person memory: Some tests of associative storage and retrieval models. Journal of Experimental Psychology: Humm Learning and Memory, 7, 440-462.

Stangor, C., \& Ruble, D. N. (1989). Strength of expectancies and memory for social information: What we remember depends on how much we know. journal of Experimental Social Psychology, 25, 18-35.

Steele, C. M., Spencer, S. J. \& Lynch, M. (1993). Self-image resilience and dissonance: The role of affirmational processes. Journal of Personality and Social Psychology, 64, 885896.

Thibodeau, R., \& Aronson, E. (1992). Taking a closer look: Reasserting the role of the self-concept in dissonance theory. Personality and Social Psychology Bulletin, 18, 591-602.

Varey, C., \& Kahneman, D. (1992). Experience extended across time: Evaluation of moments and episodes. Journal of Behavioral Decision Making, 5, 169-185.

Weiner, B. (1985). An attributional theory of achievement motivation and emotion. Psychological Revietu, 92, 548-573.

Wilson, T. D., \& Klaaren, K. J. (1992). "Expectation whirls me round": The role of affective expectations on affective experience. In M. S. Clark (Ed.), Reviezo of personality and social psychology: Enotion and social behavior (Vol. 14, pp. 1-31). Newbury Park, CA: Sage.

Wilson, T. D., Lisle, D. J, Kraft, D., \& Wetzel, C. G. (1989). Preferences as expectation-driven 
inferences: Effects of affective expectations on affective experience. Journal of Personality and Social Psychology, 56, 519-530.

Wyer, R. S. Jr., Bodenhausen, G. V., \& Srull, T. K. (1984). The cognitive representation of persons and groups and its effects on recall and recognition memory. Journal of Experimental Social Psychology, 20, 445-469.

Zajonc, R. B., Pietromonaco, P., \& Bargh, J. (1982). Independence and interaction of affect and cognition. In M.S. Clark \& S. T. Fiske (Eds.), Affect and cognition: The 17th annual Carnegie symposium on cognition (pp. 211-227). Hillsdale, NJ: Erlbaum. 